\title{
Effects of RSF-1 on proliferation and apoptosis of breast cancer cells
}

\author{
YUHUI LIU ${ }^{1}$, JUNDA GAI ${ }^{1}$, LIN FU $^{1}$, XIUWEI ZHANG ${ }^{2}$, ENHUA WANG $^{1}$ and QINGCHANG LI $^{1}$ \\ ${ }^{1}$ Staff Room of Pathology, China Medical University, College of Basic Medical Science; ${ }^{2}$ Department of Pathology, \\ The Fourth Affiliated Hospital of China Medical University, Shenyang, Liaoning 110001, P.R. China
}

Received November 27, 2017; Accepted June 18, 2018

DOI: $10.3892 / \mathrm{ol} .2018 .9172$

\begin{abstract}
Effect of interference with chromatin remodeling and spacing factor-1 (RSF-1) on proliferation and apoptosis of breast cancer cells was investigated. MCF-7 and SKBR-3 cells were cultured in vitro and were divided into 3 groups: control group, negative siRNA control group (NC) and RSF-1 siRNA group. Western blot analysis was used to detect the expression of RSF protein after interference. Cell Counting Kit-8 (CCK-8) method was used to detect the effect of RSF-1 siRNA on cell proliferation. Plate cloning assay was used to detect the effect of RSF-1 siRNA on cell clone formation ability. Annexin V/PI double staining method was used to detect the effect of RSF-1 siRNA on cell apoptosis. Effect of RSF-1 siRNA on nuclear factor $-\kappa \mathrm{B}(\mathrm{NF}-\kappa \mathrm{B})$ and its downstream signaling pathway were detected by western blot analysis. Western blot analysis showed that RSF-1 siRNA significantly downregulated the expression of RSF-1 protein in MCF-7 and SKBR-3 cells at $72 \mathrm{~h}$ after transfection $(\mathrm{P}<0.01)$. Cell proliferation assay showed that RSF-1 siRNA significantly reduced the proliferation ability and clone formation ability of MCF-7 and SKBR-3 cells compared with the control group $(\mathrm{P}<0.01)$. Annexin V/PI double staining assay results showed that compared with the control group, RSF-1 siRNA significantly increased the apoptosis rate of MCF-7 and SKBR-3 cells $(\mathrm{P}<0.01)$. Helenalin and Rsf-1 siRNA significantly reduced the expression levels of p-p65, Bcl-2, and XIAP proteins $(\mathrm{P}<0.01)$. Interfering with the expression of RSF-1, gene can effectively inhibit the proliferation of MCF-7 and SKBR-3 cells and promote their apoptosis. RSF-1 can be used as a potential new therapeutic target for the treatment of breast cancer.
\end{abstract}

Correspondence to: Dr Qingchang Li, Staff Room of Pathology, China Medical University, College of Basic Medical Science, 77 Puhe Road, Shenyang, Liaoning 110001, P.R. China

E-mail: qclicmu@163.com

Key words: RSF-1, MCF-7, SKBR-3, proliferation, apoptosis, $\mathrm{NF}-\kappa \mathrm{B}$

\section{Introduction}

Breast cancer is a common malignancy with high morbidity rate (1). Incidence of breast cancer shows an increasing trend and 1,400,000 breast cancer patients are diagnosed each year and the mortality rate is as high as $36 \%$ (2). In China, onset age of breast cancer is becoming icreasingly younger (3). The survival rate of breast cancer is closely related to the time of diagnosis; the deterioration of breast cancer, migration of breast cancer cells and drug resistance of cancer cells are still key factors for increase in mortality rate of breast cancer (4).

Progression of breast cancer is related to the imbalance between proto-oncogenes and tumor suppressor genes $(5,6)$. Remodeling and spacing factor-1 (RSF-1) is a recently identified tumor biomarker that is highly expressed in a variety of human cancer cells, and many studies have shown that its expression level is raised continuously in ovarian cancer (7), gastric cancer (8), colorectal carcinoma $(9,10)$, liver cancer $(11,12)$ and malignancies. Overexpression of RSF-1 is closely related to the occurrence and progression of cancer cells. Overexpression of Rsf-1 can promote the growth and invasion of tumor cells, which can regulate the activity of NF- $\kappa$ B pathway and the expression of MMP-2, Bcl-2, p65 and ERK protein (13). This study investigated the effects of RSF-1 expression interference on proliferation and apoptosis of breast cancer cells to provide a novel potential therapeutic target for the treatment of breast cancer.

\section{Materials and methods}

Materials and reagents. Michigan cancer foundation-7 (MCF-7) and SKBR-3 breast cancer cells purchased from (Cell Bank of the Chinese Academy of Sciences, Shanghai, China); Cell Counting Kit-8 (CCK-8), bromodeoxyuridine (BrdU) kits, and Giemsa dye solution (Sigma-Aldrich; Merck KGaA, Darmstadt, Germany); interferences RSF-1 small-interfering ribonucleic acid (siRNA), scrambled control siRNA and DharmaFECT 1 kits (Thermo Fisher Scientific, Inc., Waltham, MA, USA), RSF-1 human primary antibodies, glyceraldehyde3-phosphate dehydrogenase (GAPDH) and horseradish peroxidase (HRP)-labeled secondary antibodies (Abcam, Cambridge, MA, USA); Dulbecco's modified Eagle's medium (DMEM) (Gibco; Thermo Fisher Scientific, Inc.); apoptosis kits, TRIzol kits (Invitrogen; Thermo Fisher Scientific, 
Inc.) and 4',6-diamidino-2-phenylindole (DAPI) staining kits (Nanjing Jiancheng Biotechnology Co., Ltd., Nanjing, China). Rabbit monoclonal RSF-1 antibody (dilution 1:500; cat. no. ab109002), rabbit polyclonal GAPDH antibody (dilution 1:500; cat. no. ab37168) and secondary goat anti-rabbit (HRP) IgG antibody (dilution 1:2,000; cat. no. ab6721) were all purchased from Abcam. This study was approved by the Ethics Committee of China Medical University (Liaoning, China).

Transfection with RSF-1 siRNA. MCF-7 cells were cultured in DMEM containing double antibodies under standard condition and collected during logarithmic phase. After treatment, MCF-7 breast cancer cells were divided into two groups to be transfected with RSF-1 siRNA (RSF-1 siRNA) and negative control siRNA (NC), respectively. RSF-1 specific interference sequence: 5'-GGAAAGACAUCUCUACUAUUU-3', and sequence of scrambled control siRNA in NC, 5'-GAAGCAAC GUAUCUUGA-3'. Transient transfection was performed according to DharmaFECT 1 manual.

Verification of the interference effect of RSF-1 siRNA on messenger RNA ( $m R N A)$ via reverse transcription-quantitative polymerase chain reaction $(R T-q P C R)$. Total RNA was extracted from cells in each group using TRIzol kits, and qualified total RNA samples were subjected to reverse transcription. Total RNA was taken to synthesize complementary deoxyribonucleic acid (cDNA) using the RT Revert Aid First Strand cDNA synthesis kit. The specific reaction conditions were $42^{\circ} \mathrm{C}$ for $15 \mathrm{~min}$ and $95^{\circ} \mathrm{C}$ for $3 \mathrm{~min}$. Quantitative analysis was carried out using the ABI 7500 fluorescence PCR amplification instrument (Applied Biosystems; Thermo Fisher Scientific, Inc.). PCR amplification was performed using primers listed in Table I. $\beta$-catenin was used as an endogenous control, $\mathrm{Ct}$ values were processed using $2^{-\Delta \Delta \mathrm{Cq}}$ method (14).

Detection of RSF-1 protein expression by western blot analysis. Cultured cells were seeded in a 6-well plate at a density of $10 \%$ well. After $24 \mathrm{~h}$, supernatant was discarded. After transfection with RSF-1 siRNA and negative control siRNA, cells were cultured for $72 \mathrm{~h}$ and total protein was extracted. Protein concentration was measured and SDS-PAGE gel electrophoresis was performed with $50 \mu \mathrm{g}$ protein per lane. After gel transfer, PVDF membranes were blocked at room temperature for $1 \mathrm{~h}$, followed by incubation with rabbit monoclonal RSF-1 antibody (dilution 1:500; cat. no. ab109002) overnight at $4^{\circ} \mathrm{C}$. Membranes were washed with Tween/Tris-buffered salt solution (TBST) and incubated with secondary goat antirabbit (HRP) IgG antibody (dilution 1:2,000; cat. no. ab6721) at room temperature for $1 \mathrm{~h}$. After washing with TTBS, color development with chromo-genic solution and photography were performed.

Detection of cellular proliferation inhibition rate via $C C K-8$ assay. Cell viability was determined by CCK- 8 assay, $100 \mu \mathrm{l}$ of cell suspension containing $10^{4}$ transfected MCF-7 cells were seeded in a 96-well plate, $20 \mu \mathrm{l}$ of CCK- 8 was added into each well 24, 48 and $72 \mathrm{~h}$ later. Absorbance value (A) at $450 \mathrm{~nm}$ was measured using an enzyme microplate reader. Cell proliferation inhibition rate was calculated according
Table I. RT-qPCR primer sequences

\begin{tabular}{|c|c|}
\hline Gene & Primer sequences \\
\hline$\beta$-catenin & $\begin{array}{l}\text { F: 5'-GCTTGGAATGAGACTGCTGA-3' } \\
\text { R: } \quad \text { 5'-CTGGCCATATCCACCAGAGT-3' }\end{array}$ \\
\hline RSF-1 & $\begin{array}{ll}\text { F: } & \text { 5'-GATACTATGCGTCTCCAGCCAA-3' } \\
\text { R: } & \text { 5'-CAACTCGTTTCGATTTCTGACAA-3 }\end{array}$ \\
\hline
\end{tabular}

RSF-1, remodeling and spacing factor-1; F, forward; R, reverse.

to the following formula: Cellular proliferation inhibition rate $(\%)=\left(1-\mathrm{A}_{\text {test }} / \mathrm{A}_{\text {control }}\right) \times 100 \%$.

Plate cloning formation experiment. Cells were digested and 100 cells of each group were inoculated into a culture dish. After 24 h, cells were transfected with RSF-1 siRNA and scrambled sequence siRNA, respectively. Culture medium was changed every 2 days. Cell culture was performed for 2 weeks and was terminated when macroscopic apophyses were found in culture dishes. After washing with phosphate-buffered saline (PBS), fixation with $20 \%$ methanol for 15 min was performed. Then, an appropriate amount of Giemsa solution was added and staining was performed for $40 \mathrm{~min}$. After washing and air drying, clones were counted using a cloning counter. Cloning formation rate $(\%)=$ (number of clones/number of inoculated cells) $\mathrm{x} 100 \%$, and the inhibition rate was calculated.

Detection of cell proliferation activity via BrdU. MCF-7 cells were transfected with RSF-1 siRNA and negative control siRNA according to instructions of BrdU stain kit. Cells were cultured for $72 \mathrm{~h}$ and BrdU solution was added, followed by addition of stationary solution for fixation, and addition of tetramethylbenzidine (TMB) substrate. Absorbance at $450 \mathrm{~nm}$ was measured using the enzyme microplate reader. Results were expressed as relative light unit (RLU).

Detection of apoptosis of MCF-7 cells through Annexin V $(A V)$ /propidium iodide (PI) double staining method. MCF-7 cells were transfected with RSF-1 and negative control siRNAs. Cells were cultured for $72 \mathrm{~h}$ and digested with trypsin. After centrifugation at $2,500 \mathrm{x}$ g for $5 \mathrm{~min}$ at $4^{\circ} \mathrm{C}$, cells were washed twice with PBS, followed by addition of $5 \mu \mathrm{l} \mathrm{AV}$ and $5 \mu \mathrm{l} \mathrm{PI}$. After incubation at room temperature for $15 \mathrm{~min}$, flow cytometer (Becton-Dickinson; BD Biosciences, Franklin Lakes, NJ, USA) was used to detect apoptosis rate.

DAPI staining. MCF-7 cells were transfected with RSF-1 and negative control siRNAs. Cells were cultured for $72 \mathrm{~h}$ and washed with precooled PBS three times. DAPI solution $(1 \mu \mathrm{g} / \mathrm{ml})$ was added to each well, followed by incubation at $37^{\circ} \mathrm{C}$ for $5 \mathrm{~min}$ in a $5 \%$ carbon dioxide $\left(\mathrm{CO}_{2}\right)$ incubator. After rinsing with precooled PBS, a fluorescence microscope was used to observe and record the results in the dark.

Statistical analysis. Statistical Product and Service Solutions (SPSS) 19.0 software (International Business Machines Corporation, New York, NY, USA) was used for data analysis. 

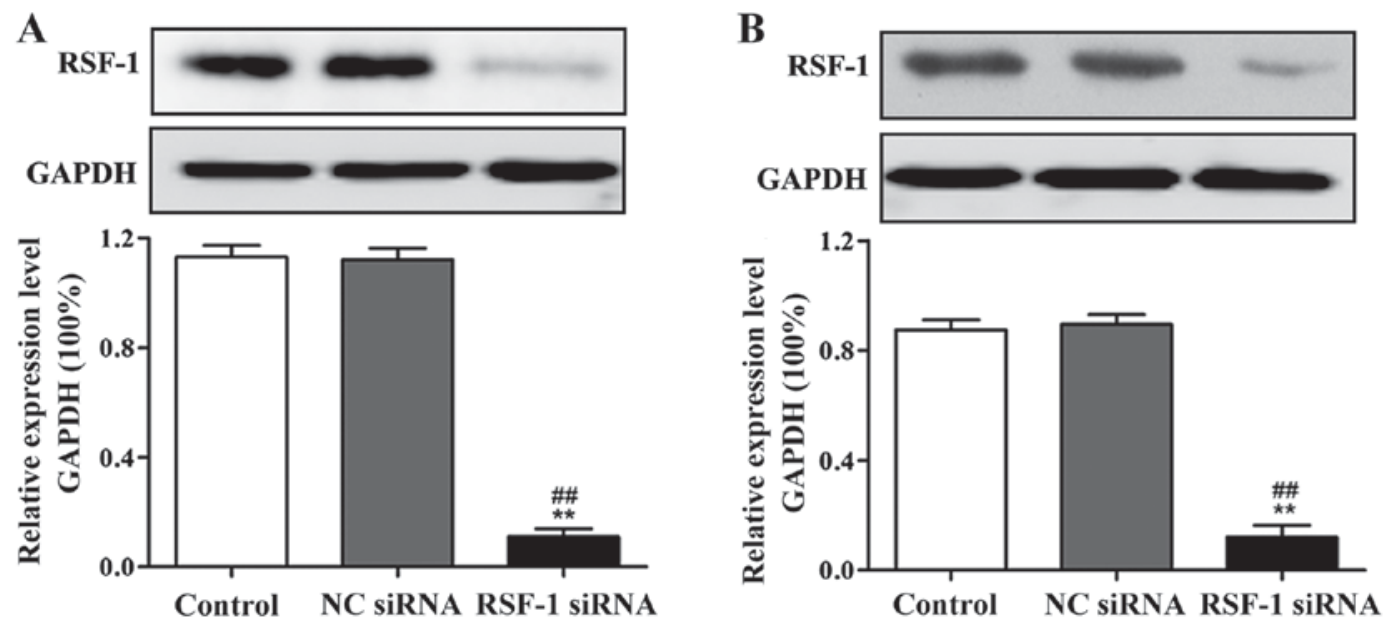

Figure 1. Western blot analysis of effect of RSF-1 siRNA interference on RSF-1 protein expression. (A) Expression of RSF-1 protein in MCF-7 cells. (B) Expression of RSF-1 protein in SKBR-3 cells. ${ }^{* *} \mathrm{P}<0.01$, compared with control group; ${ }^{\# \#} \mathrm{P}<0.01$, compared with negative control group.

A

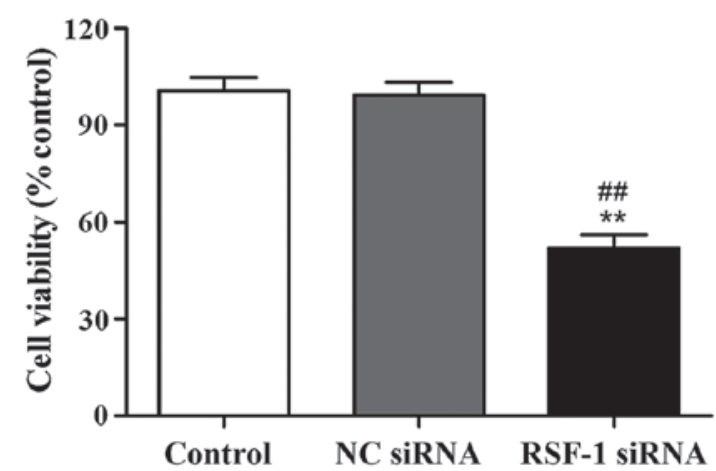

B

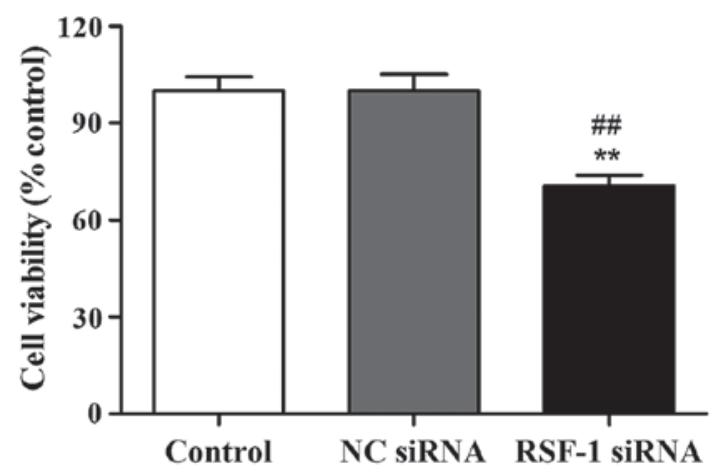

Figure 2. Cell proliferation detected by CCK-8. (A) Proliferation rate of MCF-7 cells. (B) Proliferation rate of SKBR-3 cells. ${ }^{* *} \mathrm{P}<0.01$, compared with control group; ${ }^{\# \#} \mathrm{P}<0.01$, compared with negative control group.

Data were expressed as mean \pm standard deviation. Analysis of variance (ANOVA) was used for comparison of multiple groups and the post hoc test was Dunnett test. $\mathrm{P}<0.05$ was considered to indicate a statistically significant difference.

\section{Results}

Detection of the interference effect of RSF-1 siRNA on RSF-1 $m R N A$ via protein expression. Compared with control group, RSF-1 protein expression level was significantly reduced in RSF-1 siRNA transfected MCF-7 and SKBR-3 cells $(\mathrm{P}<0.01)$ (Fig. 1)

Effect of RSF-1 siRNA on the proliferation of MCF-7 and SKBR-3 cells. CCK-8 assay was performed to detect cell proliferation of MCF-7 and SKBR-3 cells at $48 \mathrm{~h}$ after transfection. The results showed that compared with the control group, cell proliferation rate of MCF-7 and SKBR-3 cells was significantly reduced after RSF-1 siRNA transfection $(\mathrm{P}<0.01)$ (Fig. 2)

Effect of RSF-1 siRNA on the clone formation ability of MCF-7 and SKBR-3 cells. Effect of RSF-1 siRNA on clonal formation of MCF-7 and SKBR-3 cells was detected by cell clone formation assay. Compared with control group, the number of colonies formed in transfection group was significantly reduced $(\mathrm{P}<0.01)$ (Fig. 3).

Annexin V/PI staining to detect the effect of RSF-1 siRNA on cell apoptosis. AV/PI staining was used to examine the effect of RSF-1 siRNA on cell apoptosis. As shown in Fig. 4, compared with control group, RSF-1 siRNA transfection significantly increased apoptosis rate of MCF-7 and SKBR-3 cells $(\mathrm{P}<0.01)$.

Western blot analysis of the effect of RSF-1 siRNA on nuclear factor- $\kappa B(N F-\kappa B)$ and its downstream signaling pathways. As shown in Fig. 5, compared with control group, Helenalin and Rsf-1 siRNA transfection significantly reduced the expression levels of $\mathrm{p} 65, \mathrm{Bcl}-2$ and XIAP proteins, but showed no significant effects on expression of p65.

\section{Discussion}

Breast cancer seriously affects women's health. Onset age of breast cancer is becoming increasingly younger, and its incidence rate ranks first among all malignancies in urban women (15). Therefore, identification of novel targets for the treatment of breast cancer is needed. 
A
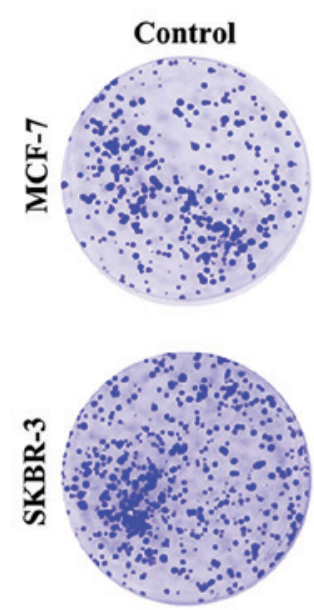

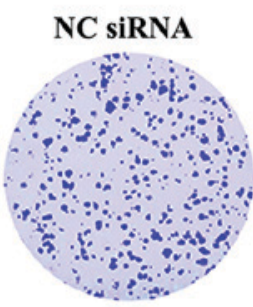

RSF-1 SiRNA
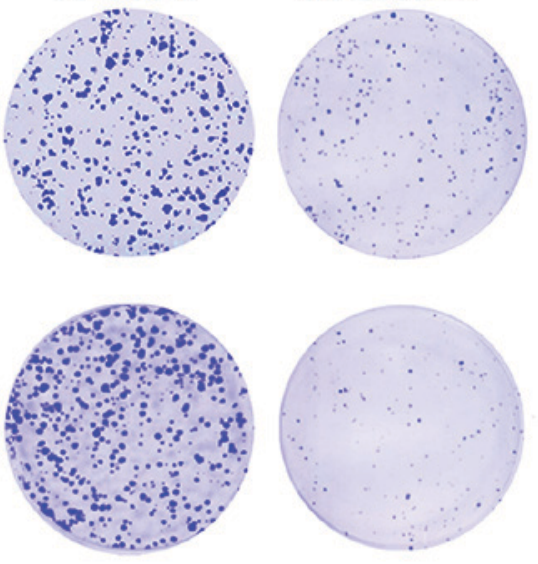
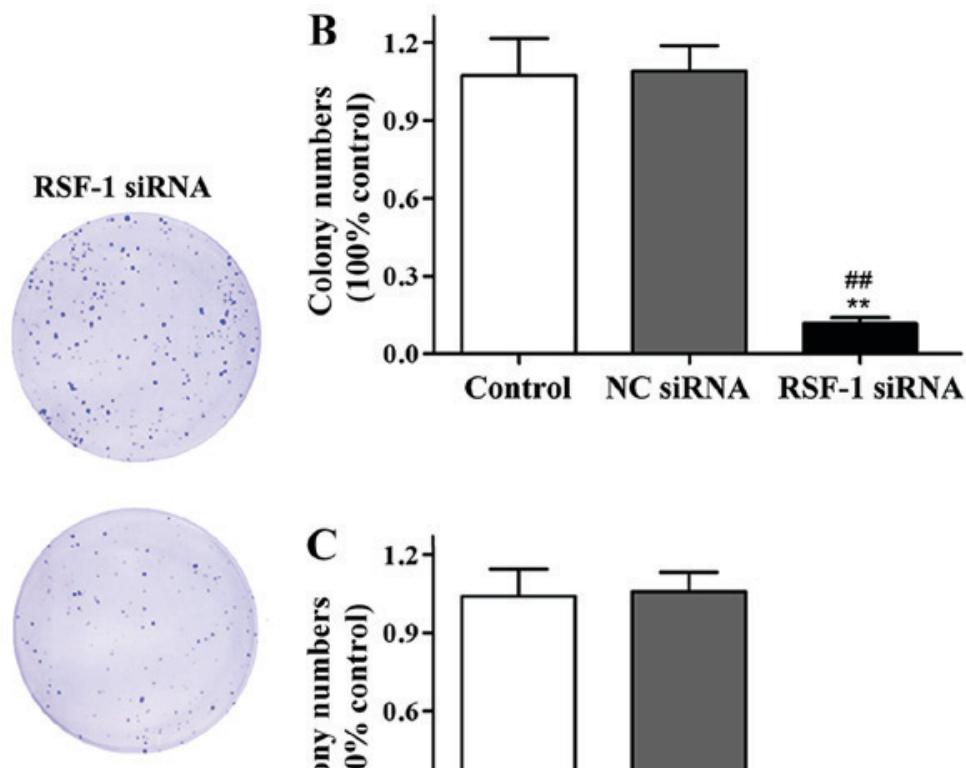

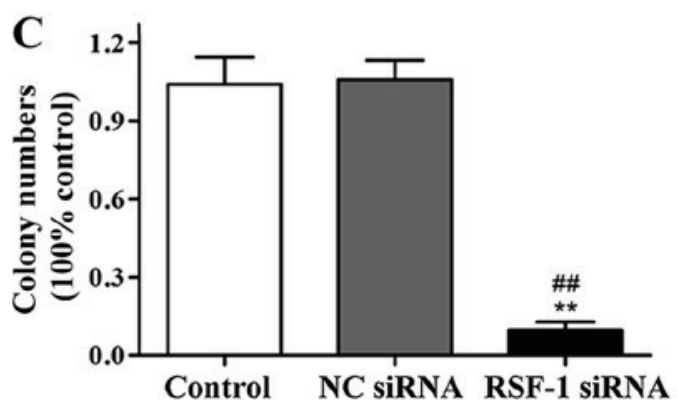

Figure 3. Cell clone formation assay results. (A) Representative results of MCF-7 and SKBR-3 cell clone formation. (B) Normalized MCF-7 cell clone formation data. (C) Normalized SKBR-3 cell clone formation data. ${ }^{* *} \mathrm{P}<0.01$, compared with control group; ${ }^{\# \#} \mathrm{P}<0.01$, compared with negative control group.
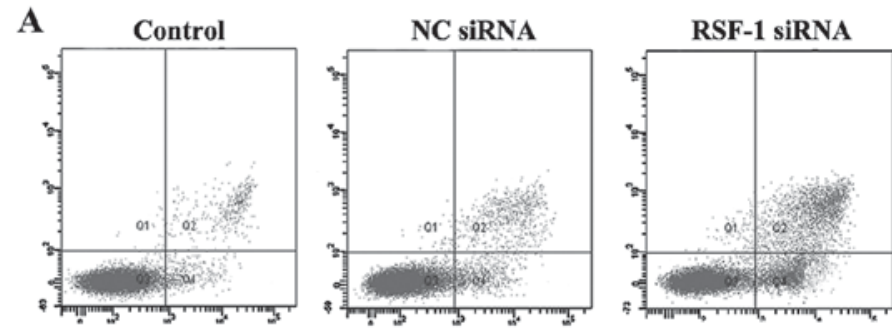

B

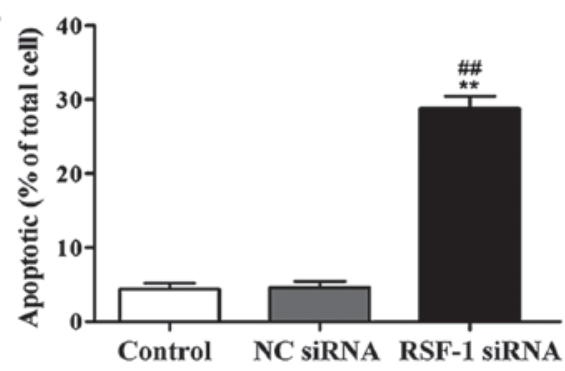

C
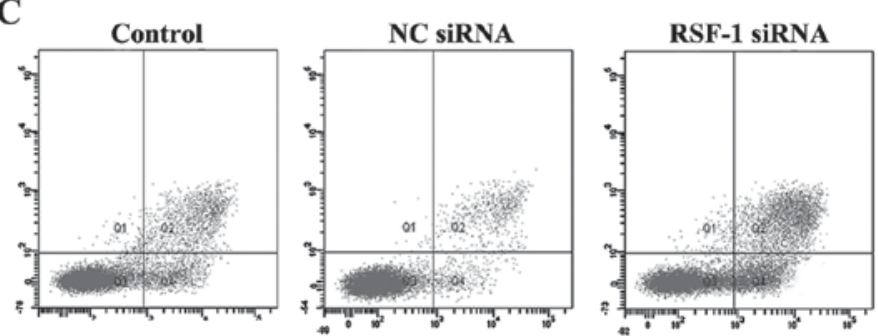

D

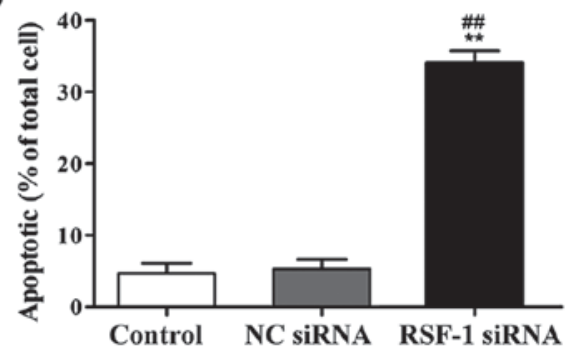

Figure 4. Annexin V/PI staining to detect the effect of RSF-1 siRNA on cell apoptosis. (A) Representative results of MCF-7 cells; (B) normalized data of MCF-7 cells; (C) representative results of SKBR-3 cells; (D) normalized data of SKBR-3 cells. ${ }^{* *} \mathrm{P}<0.01$, compared with control group; ${ }^{\# \#} \mathrm{P}<0.01$, compared with negative control group.

RSF-1 can bind to hSNF2H to form RSF. When RSF-1 binds to hSNF2H, RSF-1 assumes the role of a histone chaperone, and the RSF complex alters chromosome structure through ATPase-dependent chromatin remodeling processes (16). This process can influence gene expression, cell cycle progression, and DNA replication. The above changes in biochemical processes play a very important role in maintaining the normal cell cycle, cell death, cell apoptosis, cell senescence, and other cellular processes (17). RSF-1 is a protein with cancer promoting function. It was found that RSF-1 can promote the proliferation of tumor cells through interaction with cyclin. It has been reported that RSF-1 plays a key role in the recombination repair and non-homologous recombination repair of ovarian cancer cells (7). Chromosomal breakage may lead to apoptosis, but repair induced by RSF-1 can maintain the survival and proliferation of damaged cells, 


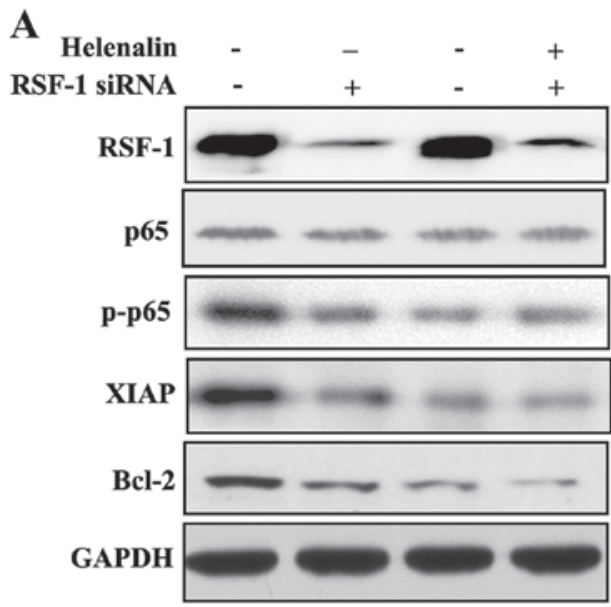

B
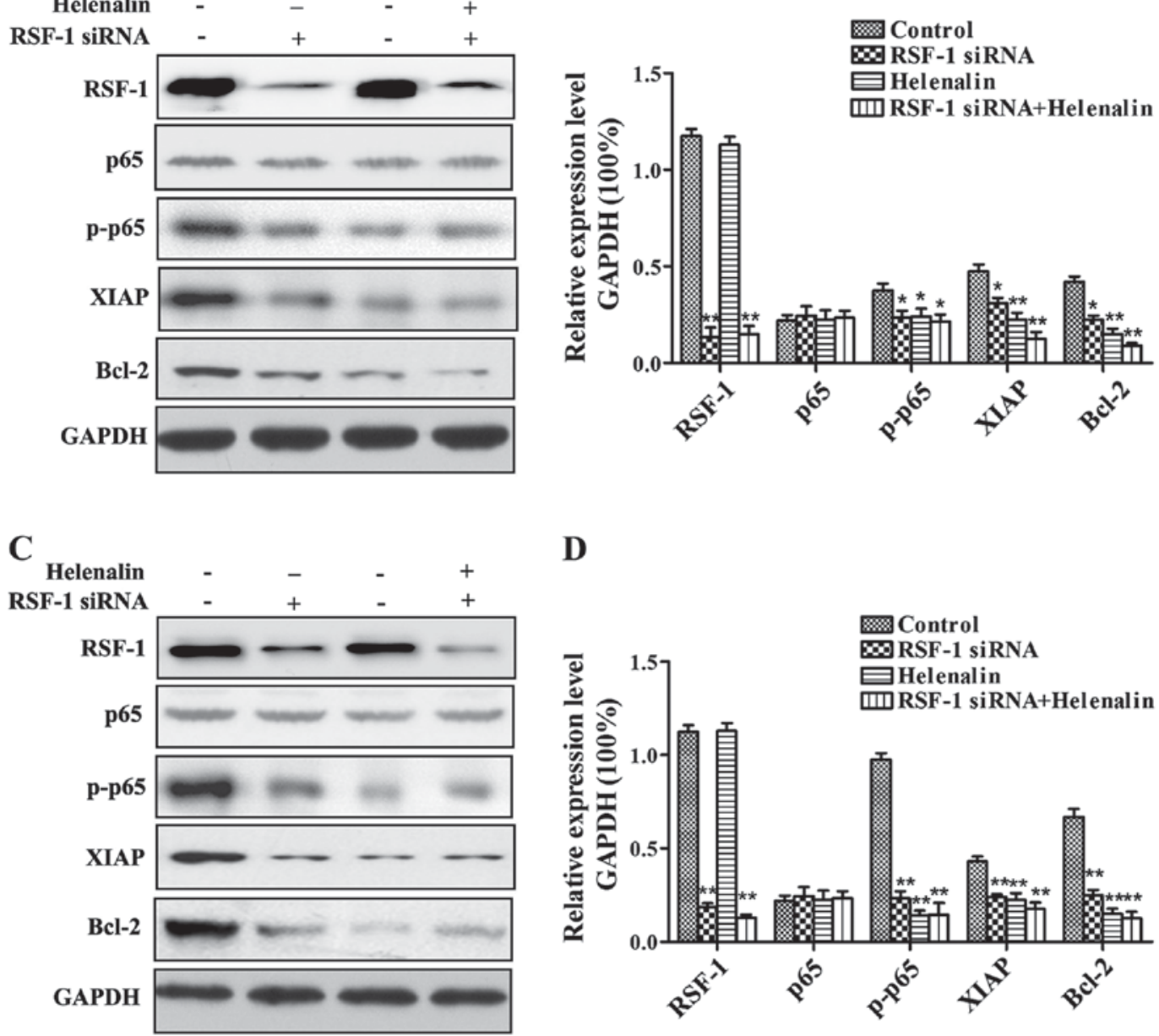

D

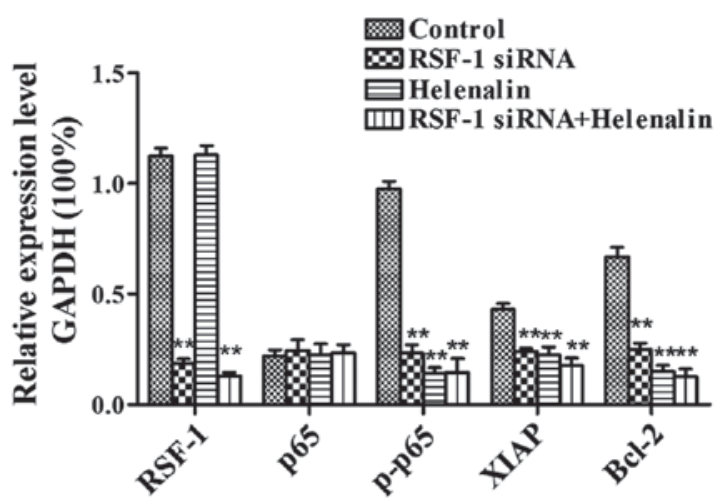

Figure 5. Western blot analysis of the effect of RSF-1 siRNA on p65 and its downstream signaling pathways. (A) Representative results of MCF-7 cells; (B) normalized data of MCF-7 cells; (C) representative results of SKBR-3 cells; (D) normalized data of SKBR-3 cells.

but this repair can only improve the survival and proliferation of mutant cells and does not restore cells to normal condition (18). RSF-1 can improve tumor cell viability by repairing abnormal chromosomes, and it can also influence tumor cell resistance to chemotherapeutic drugs by regulating $\mathrm{NF}-\kappa \mathrm{B}$ signaling pathway (19).

In this study, endogenous RSF-1 expression was interfered by siRNA interference. MCF-7 and SKBR-3 cells were cultured in vitro and divided into blank control group, negative siRNA control group (NC) and RSF-1 siRNA group. The expression of RSF protein after interference was detected by western blot analysis. Results showed that expression level of RSF-1 protein in RSF-1 siRNA transfected cells was significantly reduced. Cell proliferation assays showed that RSF-1 siRNA significantly reduced the proliferation ability and clone formation ability of MCF-7 and SKBR-3 cells compared to the blank control group. AV/PI double staining results showed that compared with the blank control group, RSF-1 siRNA significantly increased the apoptosis rate of MCF-7 and SKBR-3 cells. Helenalin and Rsf-1 siRNA significantly reduced the expression levels of p-p65, Bcl-2 and XIAP proteins, indicating that Rsf-1 can regulate the expression of $N F-\kappa B$ and its downstream signaling pathway related genes. It has been reported that breast cancer tissues with high expression level of RSF-1 are usually derived from young patients $(20,21)$.
In conclusion, this study showed that endogenous RSF-1 expression interference can significantly inhibit proliferation of human breast cancer cells and induce their apoptosis. RSF-1 may be a potential therapeutic target for breast cancer.

\section{Acknowledgements}

Not applicable.

\section{Funding}

No funding was received.

\section{Availability of data and materials}

The datasets used and/or analyzed during the present study are available from the corresponding author on reasonable request.

\section{Authors' contributions}

YL helped with transfection with RSF-1 siRNA. YL and JG performed PCR. LF and XZ were responsible for western blot analysis and CCK-8 assay. EW and QL contributed to plate cloning formation experiment. All authors read and approved the final manuscript. 


\section{Ethics approval and consent to participate}

The study was approved by the Ethics Committee of China Medical University (Liaoning, China) and informed consents were signed by the patients or the guardians.

\section{Patient consent for publication}

Not applicable.

\section{Competing interests}

The authors declare that they have no competing interests.

\section{References}

1. Hu Z, Mao JH, Curtis C, Huang G, Gu S, Heiser L, Lenburg ME, Korkola JE, Bayani N, Samarajiwa S, et al: Genome co-amplification upregulates a mitotic gene network activity that predicts outcome and response to mitotic protein inhibitors in breast cancer. Breast Cancer Res 18: 70, 2016.

2. Siegel R, Naishadham D and Jemal A: Cancer statistics, 2012. CA Cancer J Clin 62: 10-29, 2012.

3. Chen WQ, Zeng HM, Zheng RS, Zhang SW and He J: Cancer incidence and mortality in China, 2007. Chin J Cancer Res 24: $1-8,2012$

4. Macià F, Porta M, Murta-Nascimento $C$, Servitja S, Guxens M, Burón A, Tusquets I, Albanell J and Castells X: Factors affecting 5- and 10-year survival of women with breast cancer: An analysis based on a public general hospital in Barcelona. Cancer Epidemiol 36: 554-559, 2012.

5. Jones C, Ford E, Gillett C, Ryder K, Merrett S, Reis-Filho JS, Fulford LG, Hanby A and Lakhani SR: Molecular cytogenetic identification of subgroups of grade III invasive ductal breast carcinomas with different clinical outcomes. Clin Cancer Res 10 5988-5997, 2004.

6. Bange J, Zwick E and Ullrich A: Molecular targets for breast cancer therapy and prevention. Nat Med 7: 548-552, 2001.

7. Shamay M, Barak O and Shaul Y: HBXAP, a novel PHD-finger protein, possesses transcription repression activity. Genomics 79: 523-529, 2002

8. Hu BS, Yu HF, Zhao G and Zha TZ: High RSF-1 expression correlates with poor prognosis in patients with gastric adenocarcinoma. Int J Clin Exp Pathol 5: 668-673, 2012.
9. Liu S, Dong Q and Wang E: Rsf-1 overexpression correlates with poor prognosis and cell proliferation in colon cancer. Tumour Biol 33: 1485-1491, 2012.

10. Lin CY, Tian YF, Wu LC, Chen LT, Lin LC, Hsing CH, Lee SW, Sheu MJ, Lee HH and Wang YH: Rsf-1 expression in rectal cancer: with special emphasis on the independent prognostic value after neoadjuvant chemoradiation. J Clinl Pathol 65: 687, 2012.

11. Xie C, Fu L, Xie L, Liu N and Li Q: Rsf-1 overexpression serves as a prognostic marker in human hepatocellular carcinoma. Tumour Biol 35: 7595-7601, 2014.

12. Zhang X, Xu H, Gao Q, Jiang H and Li Q: The expression and significance of Rsf-1 in hepatocellular carcinoma. J Moder Oncol 1: 98-100, 2016.

13. Li Q, Dong Q and Wang E: Rsf-1 is overexpressed in non-small cell lung cancers and regulates cyclin D1 expression and ERK activity. Biochem Biophys Res Commun 420: 6-10, 2012.

14. Livak KJ and Schmittgen TD: Analysis of relative gene expression data using real-time quantitative PCR and the 2(-Delta Delta C(T)) method. Methods 25: 402-408, 2001.

15. Chan SW, Lim CJ, Guo K, Ng CP, Lee I, Hunziker W, Zeng Q and Hong W: A role for TAZ in migration, invasion, and tumorigenesis of breast cancer cells. Cancer Res 68: 2592-2598, 2008.

16. Sheu JJ, Choi JH, Yildiz I, Tsai FJ, Shaul Y, Wang TL and Shih IeM: The roles of human sucrose nonfermenting protein 2 homologue in the tumor-promoting functions of Rsf-1. Cancer Res 68: 4050-4057, 2008.

17. Loyola A, Huang JY, LeRoy G, Hu S, Wang YH, Donnelly RJ, Lane WS, Lee SC and Reinberg D: Functional analysis of the subunits of the chromatin assembly factor RSF. Mol Cell Biol 23: 6759-6768, 2003

18. Flanagan JF and Peterson CL: A role for the yeast SWI/SNF complex in DNA replication. Nucleic Acids Res 27: 2022-2028, 1999.

19. Cosma MP, Tanaka T and Nasmyth K: Ordered recruitment of transcription and chromatin remodeling factors to a cell cycleand developmentally regulated promoter. Cell 97: 299-311, 1999.

20. Hausheer FH and Yarbro JW: Diagnosis and treatment of malignant pleural effusion. Semin Oncol 12: 54-75, 1985.

21. Martínez-Moragón E, Aparicio J, Sanchis J, Menéndez R, Cruz Rogado M and Sanchis F: Malignant pleural effusion: Prognostic factors for survival and response to chemical pleurodesis in a series of 120 cases. Respiration 65: 108-113, 1998

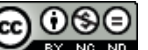

This work is licensed under a Creative Commons Attribution-NonCommercial-NoDerivatives 4.0 International (CC BY-NC-ND 4.0) License. 